\title{
Anterior Cervical Spine Osteosynthesis Complicated by Pharyngoesophageal Perforation
}

\author{
André Tokpa, Louis Derou, Ml Konan, Guy Varlet, Dominique N'dri-Oka \\ Department of Neurosurgery, CHU de Yopougon, Abidjan, Cote d'Ivoire \\ Email: ndriokad@gmail.com
}

How to cite this paper: Tokpa, A., Derou, L., Konan, M., Varlet, G. and N'dri-Oka, D. (2018) Anterior Cervical Spine Osteosynthesis Complicated by Pharyngoesophageal Perforation. Open Journal of Modern Neurosurgery, 8, 383-388.

https://doi.org/10.4236/ojmn.2018.84034

Received: December 14, 2017

Accepted: October 7, 2018

Published: October 10, 2018

Copyright $\odot 2018$ by authors and Scientific Research Publishing Inc. This work is licensed under the Creative Commons Attribution-NonCommercial International License (CC BY-NC 4.0).

http://creativecommons.org/licenses/by-nc/4.0/

\begin{abstract}
Anterior cervical spine surgery for traumatic or degenerative disease is a well-established procedure. However, complications such as pharyngoesophageal perforation can occur. In this study, we report a series of 6 pharyngoesophageal perforations after surgery. Based on the literature review, we analyzed pathogenesis, diagnosis and discussed therapeutic strategies. Three cases occurred after surgeries of traumatic cervical spine whereas the remaining were after surgeries for degenerative cervical myelopathy. The mean duration of surgery was 210 minutes. The symptoms, appearing 48 hours after surgery, were commonly hyperthermia, dysphagia, sore throat and swelling of the incision site. The diagnostic was confirmed after contrast-enhanced esophagography. The treatment strategies consisted of insertion of nasogastric feeding tube, oral intake restriction, intravenous antibiotics administration, wound drainage. Reoperation was necessary in 4 cases with removal of the hardware in three of them. One death occurred by pulmonary embolism in a tetraplegic patient. The occurrence of pharyngoesophageal perforation after cervical spine surgery can be disastrous. It can be avoided by increasing surgeon awareness during the surgical procedure. Early detection, immediate and multidisciplinary therapy are recommended to achieve the best outcomes.
\end{abstract}

\section{Keywords}

Cervical Spinal Surgery, Osteosynthesis, Complications, Pharyngo, Oesophageal Perforation

\section{Introduction}

The anterior approach of cervical spine is a well-established procedure. It is widely used for traumatic, degenerative, infectious or neoplasic cervical spine [1] 
[2] [3] [4]. It may be complicated by injuries of pre vertebral soft tissue such as the trachea, larynx, esophagus, recurrent laryngeal nerve and carotid artery [5]. Among them, pharyngo-esophageal perforations are fearful complications rarely published. Its incidence is about 3\% [3] [4] [6]. It can be responsible of mediastinitis or septicemia leading to a high mortality rate estimated between $20 \%$ to $50 \%$ even with an adequate treatment [1]. Six cases were encountered in 10 years (1995-2005) of practice in our department.

In this study, we discussed the etiopathogenesis. Afterward, we emphasized the early diagnosis and appropriate therapeutic strategy.

\section{Observations}

Case 1: A 28 years old patient underwent an anterior cervical discectomy and fusion for traumatic C5 C6 luxation. Three days after surgery, the patient complained of hyperthermia, cough with muco-purulent sputum, neck swelling and cutaneous fistula. Cervical X-ray showed a hardware failure. During re operation, we found an esophageal fistula which was drained, the metal plate was removed and a transitory jejunostomy was performed for feeding. Wide spectrum antibiotherapy was administered intravenously. The outcome was good 3 months later; the patient underwent another anterior cervical surgery to achieve the fusion.

Case 2: A 55 years old patient had C3 C6 corpectomy, iliac graft and C2 C7 arthrodesis for degenerative cervical myelopathy. She was readmitted 23 months later for pharyngeal bleeding and dysphagia. The laryngoscopy visualized the plate, a screw migration in the larynx and a surrounding edema. After jejunostomy, the screw was removed transorally. A wide spectrum antibiotherapy was administrated and the outcome was satisfying without surgery.

Case 3: A 41 years old patient had an anterior C4-C6 corpectomy with autograft and C3 C7 fixation. Three days after surgery, he started complaining of dysphagia, drooling and surgical site swelling. Cervical X rays showed a screw migration in prevertebral tissues at C7 level. Esophageal transit showed a fistula at this same level and an ultrasound revealed a pre vertebral abscess. It was then planned the drainage of the abcess and removing the migrated screw. The esophageal perforation was sutured and a temporary jejunostomy was performed at the same time by a general surgeon. Wide spectrum antibiotic was administered and the outcome was good.

Case 4: A 68 years old patient complained of dysphagia three days after a surgery for cervical myelopathy. Physical examination showed cough at feeding. Cervical X-ray was normal, but an esophagoscopy revealed a small fistula. The case was successfully managed by feeding through a nasogastric tube for one month.

Case 5: A 27 years old patient, tetraplegic after a C6 C7 traumatic luxation, complained of dysphagia, drooling and surgical site fistula two days after surgery. Cervical X-ray displayed a hardware failure (Figure 1) and the esophageal 
transit revealed a fistula (Figure 2). She underwent a surgical drainage with closure of the perforation. Subsequently, we initiated an empiric antibiotic therapy and a nasogastric feeding tube was inserted. She was drained later for a subsequent suppuration. Bedridden with a transcranial cervical traction, the patient died by pulmonary embolism.

Case 6: A 32 years old patient had hematemesis and neck swelling 12 hours after a C4 C5 anterior cervical discectomy and fixation. During an new emergency surgical procedure, we noticed a pharyngeal fistula which was sutured. We placed a nasogastric feeding tube and the patient was transfused due to heavy blood loss. The outcome was good.

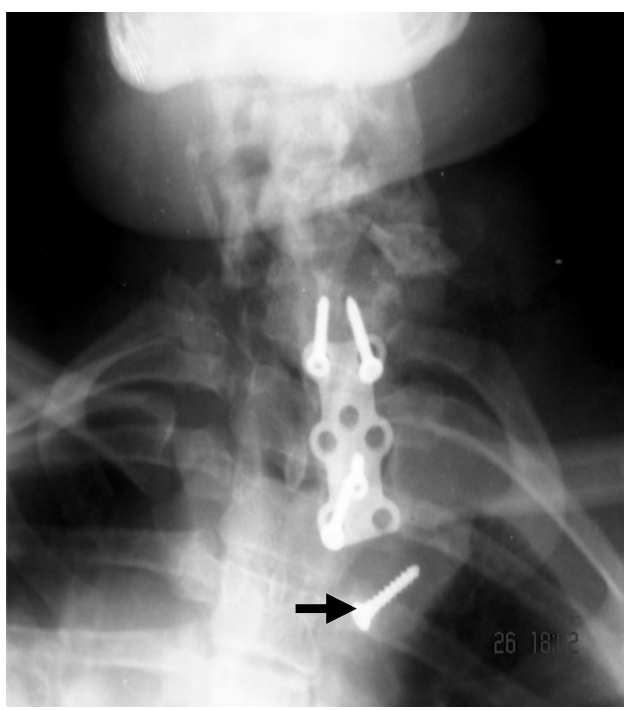

Figure 1. Anteroposterior radiographs of the cervical spine showing the lower screw loosened (arrows $\rightarrow$ ).

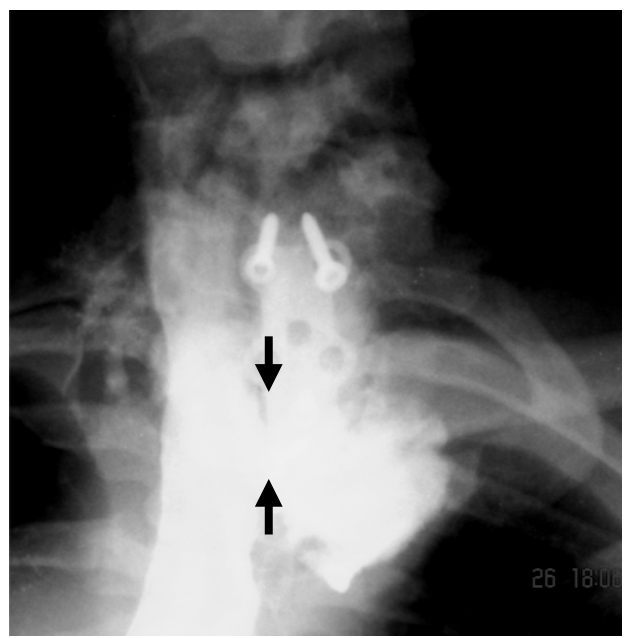

Figure 2. Post operative oesophagogram reveals persistent and extravasations of contrast shows a perforation (arrows 


\section{Discussion}

Pharyngoesophageal perforation after anterior cervical spine surgery is infrequently reported. Gaudinez reported the biggest series of 44 cases during 25 years of practice [7]. Among them, 28 cases occurred during fixation with cervical plate. In this study, the complications were involved in patients with cervical trauma. Contusion of pharynx and esophagus may occur because of their close anatomical proxymity with the cervical spine. Supporting articles reported cases of pharyngoesophageal perforations with hyper flexion or hyper extension movements during cervical spine trauma [8] [9].

\subsection{Risk Factors}

Previous studies identified several risk factors associated with this complication [2] [6] [9] [10]. Among them, the main factor is the hardware (fixation material) failure. It can be a screw migration or a loosen plate/screw. A screw migration was found in 3 of our cases. Chronic erosions by the hardware were reported in delayed onset of perforation [5] [11]. Other factors include the duration of surgery which increase the risk of necrosis in the traction area, migration of the bony graft typically in absence of fixation material [12]. Manual retractors can be particularly harmful [8]. Lastly, multiple reoperation at the same surgical site, can also be another risk factor because of the fibrosis which hinders the anatomical landmarks.

\subsection{Presenting Symptoms}

The monitoring in the first seventy-two hours is crucial. Symptoms tend to occur around 48 hours after surgery. Commonly, the patient complains of hyperthermia, neck swelling [12] [13], persisting dysphagia and odynophagia. Drooling is an alerting sign. Local evolution is toward collection and wound leakage by which we can observe pus or food debris. Emphysema is a herald sign of hollow organ perforation.

Frequently, the patient may have dysphonia, repeated pneumonia or breathing difficulties. Delayed perforations were published [1] [4] [5] [10] [14]. In those cases, chronic erosion by the hardware or screw migration was diagnosed.

\subsection{Imaging for Diagnostic}

Cervical X-ray is sufficient to visualize hardware failure. Additional clues are prevertebral soft tissue thickening and cervical emphysema [3] [15]. Cervical CT scan may fail to recognize a small perforation. Endoscopy is a valuable tool allowing direct visualization of the hardware through the perforation [3] [5] [6] [15]. Contrast-enhanced esophageal transit (swallow study) may use dyes such as Gastrografin, methylene blue, and barium [11]. Especially, methylene blue can be used during the surgery to localize the perforation site.

\subsection{Treatment Strategy}

The treatment of pharyngoesophageal perforation is an emergency and must 
involve multidisciplinary management. However, the therapeutic attitude is not univocal [9] [10] but it depends on the time of diagnosis, the size of the fistula and its location [16].

Some authors advocate only a medical treatment, especially in case of small-size dearly diagnosed fistula [3]. In this case, a diet associated with a nutritional and hydro-electrolytic rehabilitation through a nasogastric feeding tube and a wide antibiotic coverage allow closure of the fistula after 2 weeks. However, direct suture of fistula at first is still recommended with additional reinforcement of the suture by interposition of a muscular flap [3] [5] [9]. Presence of abscess increases the risk of suture loosening like our first case. In this case, a two-stage treatment is justified with drainage of the abscess and a secondary closure of the perforation.

Hardware removal is not mandatory when it is tightly fixed. This may destabilize the cervical spine especially in trauma cases [3] [13]. Appropriate nutritional and hydro-electrolytes supplementation is necessary to foster the healing process.

This retrospective series is not large enough to describe all the etiopathogeny, semiology and therapeutic characteristics of pharyngo-esophageal perforations after anterior cervical spine surgery. Our data did not provide information about the type of implant nor the surgical experience of surgeons involved in those cases.

The merit of this work is to report a complication of a very practiced surgery. We believe that this complication is underreported. Pharyngo-esophageal perforation is a serious complication enough to be suspected even in paucisymptomatic patients after surgery. The immediate implementation of an effective and multidisciplinary management can improve its prognosis.

\section{Conflicts of Interest}

The authors declare no conflicts of interest regarding the publication of this paper.

\section{References}

[1] Chataigner, H., Gangloff, S. and Onimus, M. (1997) Elimination spontanée de vis d'ostéosynthèse cervicale antérieure par les voies naturelles: A propos d'un cas. Revue de chirurgie orthopédique et réparatrice de Pappareil moteur, 83, 78-82.

[2] Geyer, T.E. and Foy, M.A. (2001) Oral Extrusion of a Screw after Anterior Cervical Spine Plating. Spine, 26, 1814-1816.

https://doi.org/10.1097/00007632-200108150-00019

[3] Landry, G., Gleizal, A., Merrot, O., Cosmidis, A. and Pignat, J.C. (2005) Perforations hypopharyngées compliquant une ostéosynthèse cervicale. Fr ORL, 89, 164-166.

[4] von Rahden, B.H., Stein, H.J. and Scherer, M.A. (2005) Late Hypopharyngo-Esophageal Perforation after Cervical Spine Surgery: Proposal of a Therapeutic Strategy. European Spine Journal, 14, 880-886. https://doi.org/10.1007/s00586-005-1006-3

[5] Yang, S.-Y., Lee, S.-B. and Cho, K.-S. (2015) Delayed Esophagus Perforation after Anterior Cervical Spine Surgery. Korean Journal of Neurotrauma, 11, 191-194. 
https://doi.org/10.13004/kjnt.2015.11.2.191

[6] Newhouse, K.E., Lindsey, R.W., Clark, C.R., Lieponis, J. and Murphy, M.J. (1989) Esophageal Perforation Following Anterior Cervical Spine Surgery. Spine, 14, 1051-1053. https://doi.org/10.1097/00007632-198910000-00004

[7] Gaudinez, R.F., English, G.M., Gebhard, J.S., Brugman, J.L., Donaldson, D.H. and Brown, C.W. (2000) Esophageal Perforations after Anterior Cervical Surgery. Journal of Spinal Disord, 13, 77-84. https://doi.org/10.1097/00002517-200002000-00015

[8] Baulot, E., Chabernaud, D., Giroux, E. and Trouilloud, P. (1996) Perforations œsophagiennes et chirurgie antérieure du rachis cervical traumatique: A propos de deux observations-Revue de la littérature. Rachis, 8, 155-160.

[9] Shenoy, S. and Raja, A. (2003) Delayed Pharyngo-Esophageal Perforation: Rare Complication of Anterior Cervical Spine Surgery-Case Reports. Neurology India, 51,534 .

[10] Martínez-Lage, J., Felipe-Murcia, M. and Azorín, L.M.-L. (2007) Late Prevertebral Abscess Following Anterior Cervical Plating: The Missing Screw. Neurocirugia, 18, 111-114. https://doi.org/10.1016/S1130-1473(07)70295-6

[11] Halani, S.H., Baum, G.R., Riley, J.P., Pradilla, G., Refai, D., Rodts Jr., G.E., et al. (2016) Esophageal Perforation after Anterior Cervical Spine Surgery: A Systematic Review of the Literature. Journal of Neurosurg. Spine, 25, 285-291. https://doi.org/10.3171/2016.1.SPINE15898

[12] Fuji, T., Kuratsu, S., Shirasaki, N., Harada, T., Tatsumi, Y., Satani, M., et al. (1991) Esophagocutaneous Fistula after Anterior Cervical Spine Surgery and Successful Treatment Using a Sternocleidomastoid Muscle Flap. A Case Report. Clinical Orthopaedics and Related Research, 267, 8-13.

[13] Roche, M., Gilly, F., Carret, J., Guibert, B., Braillon, G., Dejour, H., Editors (1989) Les perforations de l'œsophage cervical et de l'hypopharynx compliquant la chirurgie par voie antérieure du rachis cervical. Elsevier, Annales de chirurgie.

[14] Zdichavsky, M., Blauth, M., Bosch, U., Rosenthal, H., Knop, C. and Bastian, L. (2004) Late Esophageal Perforation Complicating Anterior Cervical Plate Fixation in Ankylosing Spondylitis: A Case Report and Review of the Literature. Archives of Orthopaedic and Trauma Surgery, 124, 349-353. https://doi.org/10.1007/s00402-004-0654-9

[15] Pompili, A., Canitano, S., Caroli, F., Caterino, M., Crecco, M., Raus, L., et al. (2002) Asymptomatic Esophageal Perforation Caused by Late Screw Migration after Anterior Cervical Plating: Report of a Case and Review of Relevant Literature. Spine, 27, E499-E502. https://doi.org/10.1097/00007632-200212010-00016

[16] Vrouenraets, B., Been, H., Brouwer-Mladin, R., Bruno, M. and Van Lanschot, J. (2004) Esophageal Perforation Associated with Cervical Spine Surgery: Report of Two Cases and Review of the Literature. Digestive Surgery, 21, 246-249. https://doi.org/10.1159/000079495 